\title{
Hubungan Tingkat Pengetahuan Ibu Hamil dengan Tanda Bahaya Pada Kehamilan di PMB Fauziah Hatta Palembang Tahun 2021
}

\author{
Deby Meitia Sandy ${ }^{1}$, Suci Sulistyorini ${ }^{2}$ \\ STIK Bina Husada Palembang ${ }^{1,2}$
}

Informasi Artikel :

Diterima : 28 Oktober 2021

Direvisi : 02 November 2021

Disetujui : 20 Desember 2021

Diterbitkan : 30 Desember 2021

*Korespondensi Penulis : debymeitiasandy@yahoo.com

\section{A B S T R A K}

Sekitar 830 ibu hamil meninggal setiap harinya karena komplikasi kehamilan dan persalinan. Penyebab kematian maternal antara lain perdarahan (25\%), infeksi (15\%), aborsi yang tidak aman (13\%), eklampsia $3(12 \%)$, persalinan yang buruk $(8 \%)$, penyebab obstetrik langsung lainya (8\%) dan penyebab tidak langsung (20\%), beberapa penyebab kematian maternal tersebut disebabkan adanya komplikasi yang dapat muncul melalui tanda bahaya kehamilan. Untuk mencegah timbulnya bahaya pada kehamilan maka ibu hamil perlu memeriksakan kehamilan secara rutin ke fasilitas kesehatan setempat seperti Rumah Sakit, Puskesmas, Praktik Mandiri Bidan, atau fasilitas kesehatan lainnya agar kesehatan ibu dan janin dapat terhindar dari resiko tanda bahaya kehamilan. Tujuan Penelitian ini adalah mengetahui hubungan tingkat pengetahuan ibu hamil dengan tanda bahaya pada kehamilan. Penelitian ini adalah penelitian kuantitatif dengan menggunakan metode survei analitik dengan pendekatan cross sectional. Populasi penelitian ini adalah seluruh ibu hamil yang datang memeriksakan kehamilannya di bulan April tahun 2021. Sampel yang diambil adalah 33 orang. Data disajikan dalam bentuk tabel distribusi frekuensi dan dilakukan analisis univariat dan bivariat. Hasil uji statistik didapatkan bahwa tidak ada hubungann antara tingkat pengetahuan ibu hamil dengan tanda bahaya pada kehamilan ( $p$ value $=0,199$ ). Diharapkan kepada petugas kesehatan untuk dapat memberikan penyuluhan tentang tanda bahaya pada kehamilan dan ibu hamil dapat mendeteksi dini tanda bahaya kehamilan untuk mengurangi resiko peningkatan terjadinya komplikasi selama kehamilan dan proses persalinan.

\section{Kata Kunci : Tingkat Pengetahuan, Tanda Bahaya Kehamilan}

\section{ABSTRACT}

Around 830 pregnant women die every day due to complications of pregnancy and childbirth. Causes of maternal death include bleeding (25\%), infection (15\%), unsafe abortion (13\%), eclampsia (12\%), poor delivery (8\%), other direct obstetric causes (8\%) and indirect causes $(20 \%)$, some of the causes of maternal death are due to complications that can arise through pregnancy danger signs. To prevent the occurrence of dangers in pregnancy, pregnant women need to check their pregnancy regularly at local health facilities such as hospitals, health centers, independent practice midwives, or other health facilities so that the health of the mother and fetus can be avoided from the risk of danger signs of pregnancy. The purpose of this study was to determine the relationship between the level of knowledge of pregnant women with danger signs in pregnancy. This research is a quantitative study using an analytical survey method with a cross sectional approach. The population of this study were all pregnant women who came to check their pregnancy in April 2021. The sample 
taken was 33 people. The data is presented in the form of a frequency distribution table and univariate and bivariate analysis were performed. The results of statistical tests found that there was no was no relationship between the level of knowledge of pregnant women with danger signs in pregnancy ( $p$ value $=0.199$ ). It is expected that health workers can provide counseling about danger signs in pregnancy and pregnant women can detect early pregnancy danger signs to reduce the risk of increasing complications during pregnancy and childbirth.

\section{Keywords: Knowledge Level, Danger Signs of Pregnancy}

\section{PENDAHULUAN}

Berdasarkan pengamatan World Health Organittion (WHO), sesuai dengan target terbaru yang diprogramkan Sustainable Development Goals (SDGs) pada tahun 2030 angka kematian ibu ditargetkan 70 per 100.000 kelahiran hidup dengan angka kematian bayi 12 per 1.000 kelahiran hidup (Kemenkes RI, 2016). Sekitar 830 ibu hamil meninggal setiap harinya karena komplikasi kehamilan dan persalinan. Tahun 2015 tercatat sebanyak 303.000 kasus kematian ibu yang diakibatkan komplikasi kehamilan dan persalinan. Angka Kematian Ibu dinegaranegara berkembang merupakan yang tertinggi dengan 450 kematian ibu per 100.000 kelahiran hidup. Resiko kematian tertinggi terjadi pada remaja usia kurang dari 15 tahun yang hamil dengan komplikasi dalam kehamilan dan persalinan (WHO, 2018). Penyebab kematian maternal antara lain perdarahan $(25 \%)$, infeksi $(15 \%)$, aborsi yang tidak aman (13\%), eklampsia $3(12 \%)$, persalinan yang buruk $(8 \%)$, penyebab obstetrik langsung lainya ( $8 \%$ ) dan penyebab tidak langsung (20\%), beberapa penyebab kematian maternal tersebut disebabkan adanya komplikasi yang dapat muncul melalui tanda bahaya kehamilan. Morbiditas dan mortalitas ibu hamil dapat dicegah apabila ibu hamil dan keluarganya mampu mengenali tanda bahaya kehamilan dan mencoba untuk mencari pertolongan kesehatan (Isdianty dkk, 2013).

Berdasarkan Data Profil Kesehatan Provinsi Sumatera Selatan, Kematian Ibu di Provinsi Sumatera Selatan tahun 2018 sebanyak 120 orang meningkat dari tahun
2017 sebanyak 107 orang. Penyebab kematian ibu adalah Perdarahan, Hipertensi Dalam Kehamilan (HDK), Infeksi, Gangguan Sistem Peredaran Darah (Jantung, Stroke, dll), Gangguan Metabolik (Diabetes Mellitus, dll), dan lain-lain (Dinkes Provinsi Sumsel, 2019).

Jumlah kematian ibu tahun 2017 sebanyak 7 orang dan tahun 2018 di Kota Palembang berdasarkan laporan sebanyak 15 orang dari 26.837 kelahiran hidup, tahun 2019 sebanyak 20 orang dan tahun 2020 sebanyak 59 orang. Penyebab tertinggi kematian ibu pada tahun 2020 adalah hipertensi dalam kehamilan yaitu 29\%. Upaya menurunkan kematian ibu hipertensi dalam kehamilan terus dilakukan dan waspada pada penyebab lain-lain (Dinkes Kota Palembang, 2020).

Kematian ibu menunjukan lingkup yang luas, tidak hanya terkait dengan kematian yang terjadi saat proses persalinan, tetapi mencakup kematian ibu yang sedang dalam masa hamil dan nifas. Dua kategori kematian ibu pertama adalah kematian yang disebabkan oleh penyebab langsung obsteri (direk) yaitu kematian yang diakibatkan langsung oleh kehamilan dan persalinanya, kedua adalah kematian yang disebabkan oleh penyebab tidak langung (indirek) yaitu kematian yang terjadi pada ibu hamil yang disebabkan oleh penyakit dan bukan oleh kehamilan atau persalinannya (Triana, 2015).

Tanda-tanda bahaya dalam kehamilan dapat muncul dari awal kehamilan hingga akhir kehamilan, gejalanya dapat berupa perdarahan pervaginam, mual muntah berlebihan, sakit kepala yang hebat, penglihatan kabur,nyeri perut yang hebat, gerakan janin berkurang, bengkak pada 
wajah kaki dan tangan, demam tinggi, kejang, keluar air ketuban sebelum waktunya. Munculnya tanda-tanda bahaya tersebut dapat mengindikasikan adanya bahaya atau kegawatdaruratan yang terjadi pada kehamilan (Nathania, 2014).

Pengetahuan ibu hamil tentang tanda bahaya pada kehamilan merupakan salah satu faktor yang dapat mempengaruhi ibu hamil. Semakin tinggi pengetahuan tentang tanda bahaya kehamilan maka semakin rendah kejadian bahaya pada ibu hamil, sebaliknya jika ibu hamil memiliki pengetahuan yang rendah atau tidak mengetahui tentang tanda bahaya pada kehamilan maka akan beresiko tinggi mengalami bahaya pada kehamilan. Apabila ibu hamil mengetahui tentang tanda bahaya dalam kehamilan akan lebih mewaspadai agar tidak terjadi kembali pada kehamilan yang berikutnya. Untuk mencegah timbulnya bahaya pada kehamilan maka ibu hamil perlu memeriksakan kehamilan secara rutin ke fasilitas kesehatan setempat seperti Rumah Sakit, puskesmas, Praktik Mandiri Bidan, atau fasilitas kesehatan lainnya agar kesehatan ibu dan janin dapat terhindar dari resiko tanda bahaya kehamilan. Deteksi dini dari gejala dan tanda bahaya selama kehamilan merupakan salah satu upaya yang dapat dilakukan untuk mencegah terjadinya bahaya kehamilan (Sitepu, 2019).

Berdasarkan uraian diatas, maka peneliti tertarik untuk melakukan penelitian dengan judul "Hubungan tingkat pengetahuan dengan tanda bahaya pada kehamilan di PMB Fauzia Hatta Palembang tahun 2021".

\section{METODE PENELITIAN}

Desain penelitian ini menggunakan metode survei analitik dengan pendekatan cross sectional. Dimana variabel independen (tingkat pengetahuan) dan variabel dependen (tanda bahaya kehamilan).

Populasi adalah keseluruhan objek penelitian (Notoadmodjo, 2012). Populasi dalam penelitian ini adalah seluruh ibu hamil yang berkunjung pada bulan april tahun 2021 sebanyak 33 orang. Sampel penelitian berjumlah 33 orang. Adapun data yang digunakan pada penelitian ini adalah data primer. Cara pengumpulan data pada penelitian ini menggunakan lembar kuisoner.

Analisis univariat pada penelitian ini dilakukan terhadap tiap variabel dari hasil penelitian yaitu variabel dependen dan variabel independen yang dianalisis menggunakan tabel distribusi frekuensi. Dan analisis bivariat pada penelitian ini dengan melakukan uji statistik chi square menggunakan komputerisasi, dengan tingkat kemaknaan $\alpha=0,05$. Dengan ketentuan jika $\rho$ value $\leq 0,05$ berarti ada hubungan bermakna dan jika $\rho$ value $\geq 0,05$ berarti tidak ada hubungan bemakna antara variabel dependen dan variabel independen.

\section{HASIL PENELITIAN}

\section{Analisis Univariat}

Analisis ini dilakukan untuk mengetahui distribusi frekuensi variabel dependen yaitu tanda bahaya pada kehamilan dan variabel independen yaitu tingkat pengetahuan.

Tabel 1. Distribusi Frekuensi Tanda Bahaya Kehamilan di PMB Fauzia Hatta Palembang Tahun 2021

\begin{tabular}{llcc}
\hline No & $\begin{array}{c}\text { Tanda Bahaya } \\
\text { Kehamilan }\end{array}$ & Frekuensi & \% \\
\hline 1 & Bahaya & 20 & 60,6 \\
\hline 2 & Tidak Bahaya & 13 & 39,4 \\
\hline & Jumlah & 33 & 100 \\
\hline
\end{tabular}

Berdasarkan tabel 1 diatas dari 33 responden didapatkan ibu hamil dengan mengalami tanda bahayaberjumlah 20 orang $(60,6 \%)$ dan ibu hamil yang tidak mengalami tanda bahaya pada kehamilan berjumlah 13 orang $(39,4 \%)$.

\section{Tabel 2. Distribusi Frekuensi Tingkat Pengetahuan di PMB Fauziah Hatta Palembang tahun 2021}

\begin{tabular}{llcc}
\hline No & Pengetahuan & Frekuensi & \% \\
\hline 1 & Baik & 14 & 42,4 \\
\hline 2 & Cukup & 12 & 36,4 \\
\hline 3 & Kurang & 7 & 21,2 \\
\hline & Jumlah & 33 & 100 \\
\hline
\end{tabular}


Berdasarkan tabel 2 diatas dari 33 resonden didapatkan bahwa ibu hamil yang memiliki pengetahuan yang baik berjumlah 14 orang $(42,4 \%)$, pengetahuan yang cukup berjumlah 12 orang $(36,4 \%)$, dan berpengetahuan yang kurang berjumlah 7 orang $(21,2 \%)$.

\section{Analisis Bivariat}

Analisis ini dilakukan untuk mengetahui hubungan antara variabel dependen (tanda bahaya kehamilan) dan vaiabel independen (pengetahuan). Dengan ketentuan jika $\rho$ value $\leq 0,05$ berarti ada hubungan bermakna dan jika $\rho$ value $\geq 0,05$ berarti tidak ada hubungan bemakna antara variabel dependen dan variabel independen.

\section{Tabel 3 HubunganTingkat Pengetahuan Ibu Hamil dengan Tanda Bahaya Pada Kehamilan di PMB Fauzia Hatta Palembang Tahun 2021}

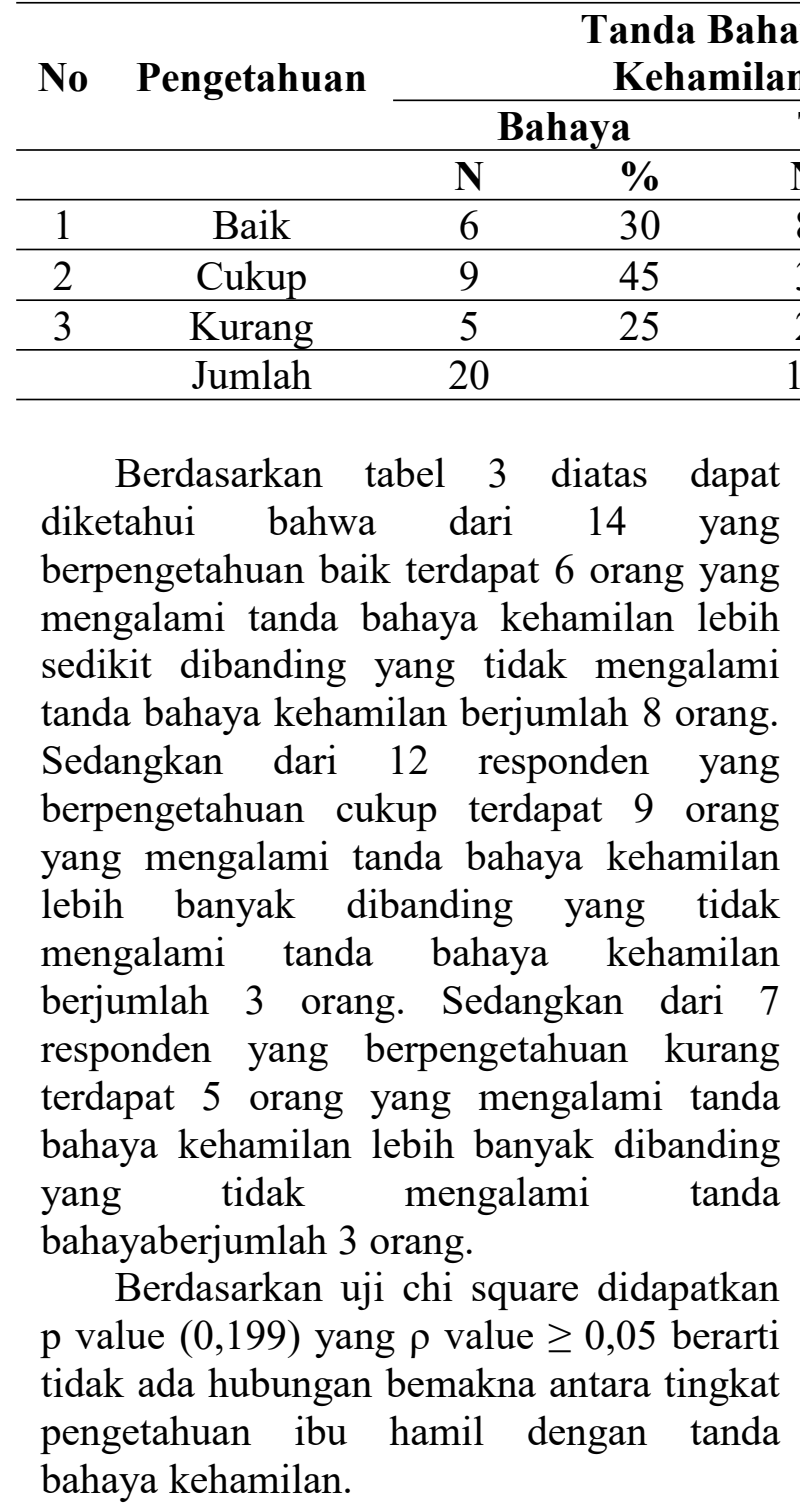

\section{PEMBAHASAN}

\section{Tingkat Pengetahuan}

Berdasarkan hasil penelitian didapatkan bahwa mayoritas ibu hamil yang berpengetahuan yang baik berjumlah 14

\section{Total \\ P value}

Tidak Bahaya

$8 \quad 61,5 \quad 14 \quad 42,4$

$3 \quad 23,1 \quad 12 \quad 36,4$

$2 \quad 15,4 \quad 131,2$

$13 \quad 33 \quad 100$

orang $(42,4 \%)$, ibu hamil berpengetahuan yang cukup sebanyak 12 orang $(36,4 \% 0$ dan paling sedikit ibu hamil berpengetahuan kurang yaitu 7 orang $(21,2 \%)$.

Dari hasil penelitian indriyani dkk tahun 2017 di wilayah kerja pukesmas bluto yaitu tingkat pengetahuan ibu hamil tentang tanda bahaya kehamilan trimester III dibagi menjadi tiga kategori yaitu baik, cukup, dan kurang. Dari hasil penelitian yang telah dilakukan peneliti mengenai tingkat pengetahuan ibu hamil tentang tanda bahaya kehamilan trimester III didapatkan hasil bahwa mayaoritas ibu hamil memiliki tingkat pengetahuan kurang 23 (69,7\%).

Menurut Bloom dan Notoatmodjo mengatakan bahwa pengetahuan merupakan domain yang sangat penting untuk terbentuknya tindakan seseorang. Dimana dalam hal ini seorang ibu hamil akan melakukan pemeriksaan kehamilan (antenatalcare) secara teratur apabila ibu tersebut mengetahui manfaat pelayanan antenatal terhadap kehamilan.

Menurut handayani tahun 2020 yaitu tingkat pengetahuan ibu hamil juga dapat dipengaruhi oleh tingkat pendidikan ibu. Pendidikan meliputi pengajaran keahlian khusus dan juga sesuatu yang tidak dapat 
dilihat tetapi lebih mendalam yaitu pemberian pengetahuan, pertimbangan dan kebijakan. Sehingga pendidikan dan pengetahuan saling berkaitan. Wanita yang berpendidikan akan membuat keputusan yang benar dalam memperhatikan kesehatan anak-anaknya serta kesehatan dirinya sendiri. Dan pengalaman kehamilan terdahulu juga dapat mempengaruhi tingkat pengetahuan ibu tentang tanda bahaya kehamilan dikarenakan ibu sudah pernah medapatkan pendidikan kesehatan pada kehamilan pertama dan ibu sudah pernah mengalami kehamilan sebelumnya sehingga ibu lebih bisa menjaga dan mengerti tentang tanda bahaya kehamilan

Menurut Yohanasari (2011) pengetahuan tentang tanda bahaya kehamilan merupakan hak yang penting untuk diketahui oleh masyarakat, khususnya ibu hamil. Hal ini penting karena jika diketahui tanda bahaya dalam kehamilan diketahui sejak dini, maka penanganan akan lebih cepat.

Menurut peneliti berdasarkan hasil sebagian ibu hamil yang sudah mengetahui tanda-tanda bahaya kehamilan, karena ibu hamil ada yang membaca dari buku pemeriksaan kehamilan (buku KIA) dan informasi dari pengalaman kehamilan lalu. Serta jenjang pendidikan ibu juga mempengaruhi untuk pengetahuan ibu, karena ibu yang berpendidikan tinggi, akan mudah menerima informasi yang disampaikan baik dalam bentuk cetak maupun elektronik.

\section{Tanda Bahaya Pada Kehamilan}

Berdasarkan hasil penelitian didapatkan sebagian besar ibu hamil dengan mengalami tanda bahayaberjumlah 20 orang $(60,6 \%)$ dan ibu hamil yang tidak mengalami tanda bahaya pada kehamilan berjumlah 13 orang $(39,4 \%)$.

Berdasarkan hasil penelitian dari indriyani dkk tahun 2017 di wilayah kerja puskesmas bluto kecamatan bluto kabupaten sumenep bahwa mayoritas ibu hamil yang mengalami bahaya kehamilan sebanyak 5 ibu hamil mengalami bengkak pada muka dan jari-jari tangan, 4 ibu hamil mengalami pandangan mata kabur, 6 ibu hamil mengalami hipertensi/tekanan darah tinggi, 3 ibu hamil mengalami Nyeri abdomen yang hebat, 2 ibu hamil mengalami Pengeluaran Cairan Pervaginam (Ketuban Pecah Dini), dan 4 ibu hamil Perdarahan Pervaginan

Tanda-tanda bahaya kehamilan adalah tanda-tanda yang mengindikasikan adanya bahaya yang dapat terjadi selama kehamilan atau periode antenatal, yang apabila tidak dilaporkan atau tidak terdeteksi bisa menyebabkan kemtian ibu (Nugroho, 2014).

Menurut peneliti tanda bahaya kehamilan setiap ibu hamil berbeda-beda, masih banyak ibu hamil yang mengganggap hal tersebut masih wajar karena faktor ketidaktahuan akan tanda-tanda bahaya kehamilan seperti muntah berlebihan, mengalami bengkak pada tangan dan kaki, pusing dan mata berkunang-kunang. Sehingga sangat penting ibu hamil mengetahui dan rutin melakukan pemeriksaan kehamilan ke fasilitas ksehatan agar terhindar dari komplikasi masa kehamilan dan persalinan.

\section{Hubungan Tingkat Pengetahuan Ibu Hamil dengan Tanda Bahaya Pada Kehamilan}

Hasil didapatkan bahwa dari 14 yang berpengetahuan baik terdapat 6 orang yang mengalami tanda bahaya kehamilan lebih sedikit dibanding yang tidak mengalami tanda bahaya kehamilan berjumlah 8 orang. Sedangkan dari 12 responden yang berpengetahuan cukup terdapat 9 orang yang mengalami tanda bahaya kehamilan lebih banyak dibanding yang tidak mengalami tanda bahaya kehamilan berjumlah 3 orang. Sedangkan dari 7 responden yang berpengetahuan kurang terdapat 5 orang yang mengalami tanda bahaya kehamilan lebih banyak dibanding yang tidak mengalami tanda bahayaberjumlah 3 orang.

Berdasarkan uji chi square didapatkan p value $(0,199)$ yang $\rho$ value $\geq 0,05$ berarti tidak ada hubungan bemakna antara tingkat pengetahuan ibu hamil dengan tanda bahaya kehamilan.

Hal ini tidak sejalan dengan hasil penelitian Indriyani dkk tahun 2017 di Wilayah Kerja Puskesmas Bluto Kecamatan 
Bluto Kabupaten Sumenep bahwa ada hubungan antara tingkat pengetahuan ibu hamil dengan tanda bahaya pada kehamilan $(\mathrm{p}$ value $=0,000)$.

Berdasarkan penelitian dari sulasmi tahun 2014 didapatkan bahwa pengetahuan dimiliki ibu hamil tentang tanda-tanda bahaya kehamilan terlihat dari $60 \%$ responden berpengetahuan yang baik. Beberapa faktor yang seseorang umur, pendidikan, pekerjaan dan gravida responden.

Menurut Sitepu (2019) pengetahuan ibu tentang tanda bahaya dalam kehamilan sangatlah penting, jika ibu telah mengetahui tanda-tanda bahaya dalam kehamilan dan ibu mengalaminya ibu dapat langsung mengambil keputusan tindakan yang harus dilakukan untuk meminimalisir terjadinya komplikasi dan memburuknya kondisi ibu, dengan itu masalah terdeteksi lebih awal dan lebih cepat pula penanganan dilakukan.

\section{KESIMPULAN}

Dari hasil penelitian yang dilakukan di PMB Fauziah Hatta Palembang pada bulan april tahun 2021 dengan jumlah 33 responden. Dapat ditarik kesimpulan bahwa : Hasil analisis univariat didapatkan ibu hamil dengan mengalami tanda bahaya berjumlah 20 orang $(60,6 \%)$ dan ibu hamil yang tidak mengalami tanda bahaya pada kehamilan berjumlah 13 orang $(39,4 \%)$ dan ibu hamil yang memiliki pengetahuan yang baik berjumlah 14 orang $(42,4 \%)$, pengetahuan yang cukup berjumlah 12 orang $(36,4 \%)$, dan berpengetahuan yang kurang berjumlah 7 orang $(21,2 \%)$. Hasil uji chi square didaptkan bahwa tidak ada hubungan bermakna antara tingkat pengetahuan ibu hamil dengan tanda bahaya kehamilan $(\mathrm{p}$ value $=0,199)$

\section{DAFTAR PUSTAKA}

Dinas Kesehatan Provinsi Sumatera Selatan. Profil Kesehatan Sumatera Selatan Tahun 2019.

file://C:/Users/Abc/Downloads/5674452 $\underline{2-}$

Profil\%20Kesehatan\%202019\%20Data\% 202018\%20(2).pdf

Dinas Kesehatan Kota Palembang. 2020. Profil Kesehatan Kota Palembang Tahun 2020. https://dinkes.palembang.go.id/tampung/ dokumen/dokumen-176-1097.pdf

Handayani, Ririn. 2020. Upaya Peningkatan Pengetahuan Ibu Hamil Tentang Tanda Bahaya Kehamilan Dalam Menghadapi Proses Persalinan Yang Aman. Jurnal Pengabdian Masyarakat Kesehatan STIKES Pemkab Jombang Vol.6 No.2 (2020).Publish 30-09-2020. http://journal.stikespemkabjombang.ac.id /index.php/jpm/article/view/615

Indriyani, Ratna, dkk. 2018. Hubungan tingkat pengetahuan iu hamil dengan tanda bahaya kehamilan trimester III diwilayah kerja puskesmas bluto kecamatan bluto kabupaten sumenep. Jurnal Ilmu Kesehatan Vol.3 No.2 Tahun 2018. Publish 31-12-2018. https://ejournalwiraraja.com/index.php/JI $\underline{\mathrm{K} / \text { article/view/665 }}$

Isdianty, Fandiar Nur \& Ugsianik Titin. 2013. Pengetahuan tanda bahaya kehamilan dan perilaku perawatan kehamilan pada ibu hamil trimester III. Jurnal keperawatan indonesia, volume 16 no.1, maret 2013, hal 18-24 pissn 1410-4490, eissn 2354-9203 http://jki.ui.ac.id/index.php/jki/article/vie $\underline{\mathrm{w} / 15 / 15}$

Kemenkes RI. 2016. Buku Kesehatan Ibu dan Anak. Jakarta : Kementrian Kesehatan dan JICA (Japan International Coorperation Agency).

Nathania M, Sulasmi, Mohdari. 2014. Gambaran Pengetahuan Ibu Hamil Tentang Tanda Bahaya Kehamilan di Puskesmas Alalak Tengah Banjarmasin. Dinamika Kesehatan: Jurnal Kebidanan Dan Keperawatan 5 (1), 28-38, Tahun 2014. https://ojs.dinamikakesehatan.unism.ac.id /index.php/dksm/article/view/191

Notoatmodjo, Soekidjo. 2012. Meodelogi Penelitian dan kesehatan. Rineka cipta, Jakarta. 
Sitepu, Tenang Juvita dkk . 2019. Pengetahuan Ibu hamil tentang tanda-tanda bahaya kehamilan berdasarkan karakteristik di Klinik Barokah. Jurnal Ilmiah JKA (Jurnal Kesehatan Aeromedika) Vol.5 No.2 tahun 2019. Publish 30-09-2019. https://jurnal.poltekestniau.ac.id/jka/articl e/view/88/74

Triana, Ani, dkk. 2015. Buku Ajar Kebidanan Kegawatdaruratan Maternal dan Neonatal. cetakan ke-1, Yogyakarta: Deepublish.

World Health Organitation. 2018. Maternal Mortality. http://www. who.int/newsroom/factsheets/detail/maternal-mortality. (Accessed: 25th April 2018). 